\title{
Clinical pharmacist interventions during clinical rounding in a psychiatric hospital: Positive evidence for pharmacists in interdisciplinary rounding at psychiatric hospital
}

Matej Stuhec ( $\nabla$ matejstuhec@gmail.com )

University of Ljubljana, European Union

Valentina Tement

University of Ljubljana, European Union

\section{Research Article}

Keywords: Clinical Pharmacy, Psychiatry, Ward rounds, Interdisciplinary team, Hospital.

Posted Date: March 25th, 2021

DOI: https://doi.org/10.21203/rs.3.rs-343442/v1

License: (c) (1) This work is licensed under a Creative Commons Attribution 4.0 International License. Read Full License 


\section{Abstract}

Clinical pharmacists have not yet become an integral part of interdisciplinary ward rounds in most psychiatric hospitals across the European Union. This retrospective study examined the impact of the recommendations from a clinical pharmacist during hospital rounds as part of an interdisciplinary medical team in a psychiatric hospital. This retrospective observational pre-post study included all patients in a Slovenian psychiatric hospital who were hospitalized in 2019-2020. The clinical pharmacist made 315 recommendations for a total of 244 participants (average age $M=59.4$, median $=56$ ). Psychiatrists accepted 295 (93.7\%) of the recommendations. After the recommendations, the number of expressed DRPs decreased in 166 interventions (93.8\%) and the number of potential DRPs in 129 interventions (93.8\%). Three months after discharge, 222 accepted recommendations were continued (70.5\%). The most common recommendations were related to antipsychotics $(19.4 \%, \mathrm{~N}=61)$ followed by antidepressants $(16.8 \%, N=53)$. Including a clinical pharmacist in the interdisciplinary ward rounds in a psychiatric hospital reduced the number of expressed and potential DRPs with a very high recommendation acceptance rate. These results are the first in the European Union to show the benefits of including a clinical pharmacist in ward rounding.

\section{Introduction}

Mental disorders pose a high disease burden and health costs, which continue to increase with significant health, social, ethical and economic consequences in all countries. Mental disorders account for $13 \%$ of the global disease burden, and major depression alone is expected to be the largest contributor by 2030 [1]. Wittchen et al. report that the most frequent disorders in the European Union are anxiety disorders (14.0\%), insomnia (7.0\%), major depression (6.9\%), somatoform disorders $(6.3 \%)$, alcohol and drug dependence (>4\%), ADHD among youth (5\%), and dementia (1-30\%, depending on age) [2]. Though there are nonpharmacological treatment options (e.g., psychotherapy), pharmacotherapy is often necessary. Patients with mental disorders are often treated with several medications (i.e., polypharmacy) and for several diseases. This opens the risk of unnecessary polypharmacy, potentially inappropriate medications (PIMs) and irrational medication combinations. In spite of lacking evidence, patients are often treated with psychotropics to manage several conditions (e.g., insomnia, depression, and behavioral symptoms of dementia treatment)[3,4]. Consequently, there is a need for well-designed studies with strong ecological validity in clinical practice to minimize medication-related problems and plan appropriate strategies.

Inpatients in psychiatric hospitals often have treatment-resistant conditions, are concurrently treated for other diseases (e.g., diabetes, infectious diseases, seizures), and receive medication combinations that are not always evidence-based. This creates a risk of inappropriate polypharmacy, which can result in inappropriate treatment, adverse events, and treatment failures [3]. Psychotropics have a particularly high risk of potential drug-drug interactions (pDDIs), adverse events (e.g., weight gain) and PIM prescribing. A retrospective descriptive chart study in a Slovene psychiatric hospital found that $47 \%$ and $22 \%$ of the prescriptions were concomitant prescriptions of two and three antipsychotics, respectively. It also found 
many inappropriate combinations, including antipsychotic polypharmacy (APP) [4]. Clozapine prescriptions in psychiatric hospitals are less frequent than expected in patients with two unsuccessful treatments and many patients are treated with APP before clozapine initiation [5].

A promising approach to address these drawbacks for patients with mental health disorders is collaborative care that involves a clinical pharmacist, which first became more widespread in the 1990s in the US, where it demonstrated improved outcomes and medication adherence in primary care settings $[6,7]$. Outside the US, Stuhec M et al. report a decrease in medication-related problems (number of PIMs and pDDIs) and an improvement in the patients' quality of life following a clinical pharmacist's medication review service in a Slovenian nursing home [8]. There is limited research on whether these benefits also apply to psychiatric hospitals, in which patients often require complex treatments, and most studies on the topic have been conducted in the US $[6,7,8,9]$. A retrospective analysis in a Californian acute care psychiatric hospital reported a positive impact of clinical pharmacist interventions during ward rounds. The interventions had a $92.5 \%$ acceptance rate. Most frequently, they were medication discontinuations (38.5\%), laboratory monitoring (26\%), and medication order modification (13.5\%). The 200 clinical pharmacist interventions were also associated with significant cost savings and cost avoidance [9]. A 2002 study of US hospitals $(N=1081)$ found a significant inverse relationship between medical errors and pharmacist participation on medical rounds (slope $=0.6974303, p<0.001$ ), as well as with pharmacist-provided admission histories (slope $=-1.6021493, p<0.001$ ) [10]. While not obtained from a randomized study, these results suggest that pharmacist participation on ward rounds may be an important way to optimize pharmacotherapy in psychiatric hospitals. Because clinical pharmacists are usually not part of interdisciplinary medical teams in psychiatric settings in the European Union, this paper sets out to examine the impact of clinical pharmacist interventions during hospital rounds in a Slovenian psychiatric hospital.

\section{Methods}

\section{Study setting}

This study was conducted in the Ormoz Psychiatric Hospital (Psihiatrična bolnišnica Ormož), which covers approximately 300,000 inhabitants in Northeastern Slovenia. It has 120 hospital beds and provides treatment for all mental disorders, a community psychiatric service and daily hospital and outpatient service. It receives approximately 1,000 inpatients annually with an average length of stay of 28 days. It has six wards: a psychogeriatric ward, a daily hospital center, an addiction treatment center, two closed wards, and an open ward for prolonged treatment. Daily hospital activities include interdisciplinary team activities (e.g., ward rounding) and individual activities (e.g., daily conversation between patients and various healthcare professionals, occupational therapy activities, psychotherapy).

During the study period, ward rounding was done 1-2 times per week in the morning for each ward and included all interdisciplinary team members: a psychiatrist, nurse, clinical pharmacist, psychologist, occupational therapist, and a social worker. Additional ward staff members may also be involved in 
roundings as well as residents (e.g., psychiatrists, psychologists and clinical pharmacists) and students (e.g., nursing, pharmacy, psychology and occupational therapy). Ward roundings covered 10-20 patients in 60-90 minutes, included by a discussion and potential decisions within the interdisciplinary team, such as changes in patient care including pharmacotherapy. Hospital employs one board-certified clinical pharmacist specialist. Clinical pharmacists may suggest interventions to ward psychiatrists during the roundings who need to confirm it. Each intervention is recorded in electronic patient records. Clinical pharmacists monitor all interventions and adjust them at subsequent ward roundings if necessary. He plays an important role in the team by contributing his expertise through medication recommendations and by designing and monitoring treatment plans. He does not measure clinical outcomes, but does have access to patient health data. The inclusion of a clinical pharmacist in the interdisciplinary team is a care standard since 2018 (as per the Slovenian Pharmacy Act), but not practiced in all psychiatric hospitals.

\section{Study design}

We designed a retrospective observational pre-post study that included all inpatients at the Ormoz Psychiatric Hospital between November 2019 and December 2020 for whom the clinical pharmacist provided recommendations. There was no additional selection criteria or a control group. The patients' data were retrieved from their electronic health records or hospital databases and were analyzed from when the time the clinical pharmacist provided recommendations to three months after hospital discharge. Clinical outcomes were not measured.

Drug-related problems (DRPs) were classified according to the Slovenian classification of drug-related problems (DRP-SLO-V1) with some adjustments. DRPs were identified as potential or expressed [11]. Potential DRPs were described in terms of risk factors for the DRPs to arise in practice. We examined if any potential DRPs occurred by 3 months after discharge.

We identified problems related to treatment effectiveness, adverse events (treatment safety), and unnecessary drug treatment problems (e.g., no indication). The interventions were categorized into drug discontinuation, drug initiation, and drug regimen adjustment. The clinical pharmacist interventions were considered effective if risk factors for DRPs were not present at 3 months after discharge, based on patients' medical documentation. A similar methodology was used in our previous paper on a nursing home setting [8].

\section{Outcomes}

The primary outcome measure was the acceptance rate (\%) of interventions. The secondary outcome measures were the continuation rate 3 months after discharge (\%) and the difference in the total numbers of DRPs for each patient at the discharge. We only included clinical pharmacist interventions related to ward rounding.

\section{Data collection and analysis}

The patient data were collected by Valentina Tement (MPharm student) and Matej Stuhec (first author), who has been working in a psychiatric hospital setting for over a decade. We calculated the baseline characteristics of patients as the mean \pm standard deviation as well as the differences before and after 
the interventions. SPSS Statistics 22.0 was used for statistical analysis. This study used the STROBE Statement checklist for observational studies [12]

\section{Ethical declaration}

All methods were carried out in accordance with relevant guidelines and regulations. Informed consent was not necessary from all subjects in Slovenia, because this was a retrospective chart study which was approved by the National Medical Ethics Committee of the Republic of Slovenia in 2021 (Number 0120 18/2021/3; approved 11.3.2021) and the Committee waived the requirement of informed consent.

\section{Results}

\section{General results}

The study included 224 patients (average age $=59.4, S D=16.9$, median $=56,140$ men and 104 women). The clinical pharmacist attended 75 ward roundings during the study period and gave 315 recommendations (4.2 per ward rounding), excluding 9 recommendations with missing data which were not included in the final analysis.

\section{Drug-related problems and outcomes}

In total, the clinical pharmacist provided 315 separate recommendations, which were most commonly dose adjustments in $37.8 \%$ of all recommendations $(N=119)$, followed by medication initiation $(24.4 \%, N$ = 77), medication discontinuation $(24.4 \%, N=77)$ and other interventions $(13.3 \%, N=42)$. The psychiatrists accepted 295 (93.7\%) of them and rejected 20 (6.3\%) proposed interventions (Flowchart).

Out of the total 315 DRPs, $56.2 \%(N=177)$ were expressed and $43.8 \%$ were potential DRPs $(N=138)$. After the clinical pharmacist's recommendations, the number of both expressed and potential DRPs decreased by $93.8 \%$ to 11 and 9 DRPs, respectively.

The recommended interventions were most commonly related to treatment effectiveness $(61.0 \%$ of all recommendations, $N=192,91.2 \%$ acceptance rate), followed by inappropriate treatment $(34.9 \%, N=110$, $97.2 \%$ acceptance rate) and medication safety $(4.1 \%, N=13,100 \%$ acceptance rate). No adverse events from accepted recommendations were observed by the time of hospital discharges. The clinical pharmacist most frequently provided recommendations at the psychogeriatric ward $(40.6 \%, N=128)$, followed by the addiction department $(26.0 \%, N=82)$, closed and open wards $(22.6 \%, N=71)$ and the daily hospital $(9.8 \%, N=31)$.

Three months after discharge, $70.5 \% \mathrm{~b}$ of all proposed recommendations were maintained, $28.6 \%$ were not continued and $1.0 \%$ had missing data. The DRPs were most frequently related to the treatment of mental disorders, followed by the treatment of cardiovascular diseases. In terms of medication type, recommendations were most commonly given for antipsychotics $(19.4 \%, N=61)$ followed by antidepressants $(16.8 \%, N=53)$, antihypertensive medications $(18.8 \%, N=59)$, anxiolytics $(8.2 \%, N=26)$, 
antibiotics $(7.0 \%, N=22)$, hypnotics $(4.1 \%, N=13)$, analgesics, antiepileptics and beta blockers $(3.8 \%$ each, $N=12$ each) and other medications $(14.3 \%, N=45)$.

b Antibiotics were included in 22 different interventions (7.0\%). See Table 1 for detailed information on treatment guidelines adherence and clinical pharmacist recommendations. All antibiotic treatments were effective and patients did not require additional treatment. The psychiatrists accepted all proposed recommendations. 
Table 1

Proposed and accepted recommendations in antibiotic therapy; L(UTI): lower urinary tract infection; $\mathrm{U}(\mathrm{UTI})$ : upper urinary tract infection.

\begin{tabular}{|c|c|c|c|c|}
\hline $\begin{array}{l}\text { Case } \\
\text { number }\end{array}$ & Problem & $\begin{array}{l}\text { Clinical pharmacists } \\
\text { recommendations }\end{array}$ & $\begin{array}{l}\text { Acceptance } \\
\text { (yes/no) }\end{array}$ & Age \\
\hline $\begin{array}{l}1 \mathrm{a}, 1 \mathrm{~b} \\
1 \mathrm{c}, 1 \mathrm{~d} \\
1 \mathrm{e}, 1 \mathrm{f}\end{array}$ & $\begin{array}{l}\text { Ciprofloxacin treatment } \\
\text { for L(UTI) }\end{array}$ & Cefuroxime was suggested & YES & $\begin{array}{l}72 \text { and } 71 \\
\text { and } 79 \text { and } \\
87 \text { and } 87 \\
\text { and } 90\end{array}$ \\
\hline 2 & $\begin{array}{l}\text { Levofloxacin treatment for } \\
\text { L(UTI) }\end{array}$ & Cefuroxime was suggested & YES & 76 \\
\hline 3 & $\begin{array}{l}\text { Antibiotic selection for } \\
\text { L(UTI) }\end{array}$ & $\begin{array}{l}\text { Amoxicillin treatment for } \\
\text { L(UTI) in line with } \\
\text { antibiogram results }\end{array}$ & YES & 64 \\
\hline $4 a, 4 b$ & $\begin{array}{l}\text { Antibiotic selection for } \\
\text { L(UTI) }\end{array}$ & $\begin{array}{l}\text { Nitrofurantoin was } \\
\text { suggested }\end{array}$ & YES & 79 and 80 \\
\hline 5 & Fosfomycin for U(UTI) & Cefuroxime was suggested & YES & 79 \\
\hline 6 & $\begin{array}{l}\text { Antibiotic selection for } \\
\text { L(UTI) }\end{array}$ & $\begin{array}{l}\text { Norfloxacin treatment for } \\
\text { L(UTI) in line with } \\
\text { antibiogram results }\end{array}$ & YES & 93 \\
\hline $\begin{array}{l}7 a, 7 b, \\
7 c\end{array}$ & $\begin{array}{l}\text { Ciprofloxacin treatment } \\
\text { for } \mathrm{L}(\mathrm{UTI})\end{array}$ & $\begin{array}{l}\text { Nitrofurantoin was } \\
\text { suggested }\end{array}$ & YES & $\begin{array}{l}67 \text { and } 68 \\
\text { and } 68\end{array}$ \\
\hline 8 & $\begin{array}{l}\text { Nitrofurantoin dose } \\
\text { adjustment for L(UTI) }\end{array}$ & Dose adjustment & YES & 40 \\
\hline 9 & $\begin{array}{l}\text { Co-trimoxazole treatment } \\
\text { for } L(U T I) \text { together with } \\
\text { quetiapine }\end{array}$ & $\begin{array}{l}\text { Nitrofurantoin was } \\
\text { suggested }\end{array}$ & YES & 49 and 50 \\
\hline 10 & $\begin{array}{l}\text { Nitrofurantoin for L(UTI) } \\
\text { and kidney failure }\end{array}$ & Cefuroxime was suggested & YES & 80 \\
\hline 11 & $\begin{array}{l}\text { Moxifloxacin for Chronic } \\
\text { bronchitis }\end{array}$ & Amoxicillin was suggested & YES & 54 \\
\hline $\begin{array}{l}12 a, b, \\
c\end{array}$ & $\begin{array}{l}\text { Other interventions } \\
\text { (treatment duration, } \\
\text { administration) }\end{array}$ & Different recommendations & YES & $49,80,90$ \\
\hline
\end{tabular}

\section{Antipsychotic therapy}

Antipsychotics were included in 61 different interventions (19.4\%). See Table 2 for information on treatment guidelines adherence and clinical pharmacist recommendations. 
Table 2

Proposed and accepted recommendations in antipsychotic therapy; ADHD = Attention deficit hyperactivity disorder; SR = sustained release form.

\begin{tabular}{|c|c|c|c|c|}
\hline $\begin{array}{l}\text { Case } \\
\text { number }\end{array}$ & Problem & Age & Clinical pharmacists recommendations & $\begin{array}{l}\text { Acceptance } \\
\text { (yes/no) }\end{array}$ \\
\hline 1 & $\begin{array}{l}\text { Aripiprazole, } \\
\text { levomepromazine } \\
\text { and zuclopentixol }\end{array}$ & 48 & Aripiprazole discontinuation & YES \\
\hline 2 & $\begin{array}{l}\text { Quetiapine and } \\
\text { insomnia }\end{array}$ & 41 & Quetiapine dose adjustment & YES \\
\hline 3 & $\begin{array}{l}\text { Sulpiride } \\
\text { treatment }\end{array}$ & 42 & Sulpiride dose adjustment & YES \\
\hline 4 & $\begin{array}{l}\text { Pregabalin } \\
\text { treatment in } \\
\text { patients with } \\
\text { antipsychotics }\end{array}$ & 66 & Pregabalin dose adjustment & NO \\
\hline $5 a, 6 b$ & $\begin{array}{l}\text { Amisulpiride for } \\
\text { acute psychotic } \\
\text { episodes }\end{array}$ & 45,45 & $\begin{array}{l}\text { Amisulpiride initiation, Amisulpiride } \\
\text { discontinuation }\end{array}$ & YES, YES \\
\hline $\begin{array}{l}7 \mathrm{a}, 8 \mathrm{~b} \\
9 \mathrm{c}, 10 \mathrm{~d} \\
11 \mathrm{e} \\
12 \mathrm{f} \\
13 \mathrm{~g}, \\
14 \mathrm{~h} \\
15 \mathrm{i}\end{array}$ & $\begin{array}{l}\text { Quetiapine } \\
\text { treatment }\end{array}$ & $\begin{array}{l}62,83 \\
35,84 \\
39,38 \\
41,40 \\
40\end{array}$ & $\begin{array}{l}\text { Quetiapine dose adjustment; Switching to } \\
\text { risperidone; Quetiapine discontinuation; } \\
\text { Quetiapine dose adjustment; Quetiapine } \\
\text { discontinuation; Quetiapine SR initiation; } \\
\text { Quetiapine dose adjustment; Quetiapine } \\
\text { dose adjustment; Quetiapine dose } \\
\text { adjustment }\end{array}$ & $\begin{array}{l}\text { YES, YES, } \\
\text { YES, YES, } \\
\text { YES,YES, } \\
\text { YES, YES, } \\
\text { YES }\end{array}$ \\
\hline $\begin{array}{l}16 \mathrm{a} \\
17 \mathrm{~b} \\
18 \mathrm{c}\end{array}$ & $\begin{array}{l}\text { Olanzapine } \\
\text { treatment }\end{array}$ & $\begin{array}{l}45,74 \\
59\end{array}$ & $\begin{array}{l}\text { Olanzapine dose adjustment; Switching } \\
\text { to risperidone; Switching to quetiapine }\end{array}$ & $\begin{array}{l}\text { YES, YES, } \\
\text { YES }\end{array}$ \\
\hline 19 & $\begin{array}{l}\text { Aripiprazole and } \\
\text { sleep disorder }\end{array}$ & 45 & Monitoring and dose adjustment & YES \\
\hline 20 & $\begin{array}{l}\text { Aripiprazole and } \\
\text { olanzapine in } \\
\text { pacient with } \\
\text { weight gain }\end{array}$ & 45 & $\begin{array}{l}\text { Aripirazole discontinuation and } \\
\text { olanzapine initiation }\end{array}$ & YES \\
\hline 21 & $\begin{array}{l}\text { Haloperidol and } \\
\text { quetiapine }\end{array}$ & 92 & Haloperidol discontinuation & YES \\
\hline 22 & $\begin{array}{l}\text { Quetiapine and } \\
\text { dry mouth }\end{array}$ & 64 & Quetiapine discontinuation & NO \\
\hline 23 & $\begin{array}{l}\text { Carbamazepine } \\
\text { in the treatment } \\
\text { of epilepsy }\end{array}$ & 52 & Dose adjustment & YES \\
\hline 24 & $\begin{array}{l}\text { Quetiapine and } \\
\text { sertraline } \\
\text { treatment }\end{array}$ & 54 & Dose adjustment & YES \\
\hline
\end{tabular}




\begin{tabular}{|c|c|c|c|c|}
\hline $\begin{array}{l}\text { Case } \\
\text { number }\end{array}$ & Problem & Age & Clinical pharmacists recommendations & $\begin{array}{l}\text { Acceptance } \\
\text { (yes/no) }\end{array}$ \\
\hline 25 & $\begin{array}{l}\text { No clear } \\
\text { indication for } \\
\text { Risperidone }\end{array}$ & 80 & Risperidone discontinuation & YES \\
\hline 26 & $\begin{array}{l}\text { Sulpiride andq in } \\
\text { patient with QT } \\
\text { prolongation }\end{array}$ & 29 & $\begin{array}{l}\text { Combination discontinuation } \\
\text { (monoterapy) }\end{array}$ & YES \\
\hline 27 & $\begin{array}{l}\text { Risperidone and } \\
\text { insomnia }\end{array}$ & 78 & Switching to quetiapine & YES \\
\hline 28 & $\begin{array}{l}\text { Clozapine, } \\
\text { olanzapine, } \\
\text { aripiprazole }\end{array}$ & 29 & Olanzapine discontinuation & YES \\
\hline 29 & $\begin{array}{l}\text { Clomethiazole } \\
\text { and zolpidem in } \\
\text { patient with } \\
\text { dementia }\end{array}$ & 80 & $\begin{array}{l}\text { Clomethiazole dose adjustment, zolpidem } \\
\text { discontinuation, quetiapine initiation }\end{array}$ & YES \\
\hline 30 & $\begin{array}{l}\text { Diazepam, } \\
\text { quetiapine and } \\
\text { clomethiazole }\end{array}$ & 53 & $\begin{array}{l}\text { Diazepam discontinuation, quetiapine } \\
\text { discontinuation }\end{array}$ & YES \\
\hline 31 & $\begin{array}{l}\text { Quetiapine and } \\
\text { blood count }\end{array}$ & 84 & Switching to zuclopentixol & YES \\
\hline 32 & $\begin{array}{l}\text { Haloperidol and } \\
\text { olanzapine and } \\
\text { psychosis }\end{array}$ & 30 & $\begin{array}{l}\text { Haloperidol discontinuation and } \\
\text { switching to amisulpiride }\end{array}$ & YES \\
\hline 33 & $\begin{array}{l}\text { Haloperidol, } \\
\text { olanzapine and } \\
\text { blood count }\end{array}$ & 50 & Olanzapine discontinuation & YES \\
\hline 34 & $\begin{array}{l}\text { Aripiprazole and } \\
\text { patient with } \\
\text { psychosis }\end{array}$ & 26 & Switching to amisulpiride & YES \\
\hline 35 & $\begin{array}{l}\text { Pregabalin and } \\
\text { sulpiride } \\
\text { concomitantly }\end{array}$ & 49 & Sulpiride discontinuation & NO \\
\hline $\begin{array}{l}36 \mathrm{a}, \\
37 \mathrm{~b}\end{array}$ & $\begin{array}{l}\text { Sulpiride } \\
\text { treatment }\end{array}$ & 39,45 & Sulpiride dose adjustment & YES, YES \\
\hline $\begin{array}{l}38 a, \\
39 b\end{array}$ & $\begin{array}{l}\text { Risperidone and } \\
\text { schizophrenia }\end{array}$ & 81,80 & $\begin{array}{l}\text { Risperidone dose adjustment; Risperidone } \\
\text { dose adjusment }\end{array}$ & YES, YES \\
\hline 40 & $\begin{array}{l}\text { Quetiapine and } \\
\text { nitrazepam } \\
\text { treatment }\end{array}$ & 72 & Monitoring and dose adjustment & YES \\
\hline
\end{tabular}




\begin{tabular}{|c|c|c|c|c|}
\hline $\begin{array}{l}\text { Case } \\
\text { number }\end{array}$ & Problem & Age & Clinical pharmacists recommendations & $\begin{array}{l}\text { Acceptance } \\
\text { (yes/no) }\end{array}$ \\
\hline 41 & $\begin{array}{l}\text { Amisulpiride and } \\
\text { patient with low } \\
\text { blood pressure }\end{array}$ & 60 & Amisulpiride dose adjustment & YES \\
\hline 42 & $\begin{array}{l}\text { Vortioxetine and } \\
\text { sulpiride and } \\
\text { depression }\end{array}$ & 55 & $\begin{array}{l}\text { Switching vortioxetine to venlafaxine, } \\
\text { quentiapine initiation, sulpirid } \\
\text { discontinuation }\end{array}$ & YES \\
\hline 43 & $\begin{array}{l}\text { Quentiapine in } \\
\text { patient with QT } \\
\text { prolongation }\end{array}$ & 86 & Switching to paliperidone & YES \\
\hline 44 & $\begin{array}{l}\text { Risperidon, } \\
\text { atomoxetine, } \\
\text { quetiapine, } \\
\text { diazepam, } \\
\text { sodium valprote } \\
\text { and patient with } \\
\text { ADHD }\end{array}$ & 38 & $\begin{array}{l}\text { Risperidon discontinuation, diazepam } \\
\text { dose adjustment, sodium valproate dose } \\
\text { adjustment }\end{array}$ & YES \\
\hline 45 & $\begin{array}{l}\text { Quetiapine and } \\
\text { hypersomnia }\end{array}$ & 29 & $\begin{array}{l}\text { Quetiapine dose adjustment and } \\
\text { monitoring }\end{array}$ & YES \\
\hline 46 & $\begin{array}{l}\text { No clear } \\
\text { indication for } \\
\text { olanzapine }\end{array}$ & 61 & Olanzapine discontinuation & YES \\
\hline 47 & $\begin{array}{l}\text { No clear } \\
\text { indication for } \\
\text { haloperidol }\end{array}$ & 58 & Haloperidol discontinuation & YES \\
\hline 48 & $\begin{array}{l}\text { Patient with } \\
\text { dementia and } \\
\text { isomnia }\end{array}$ & 85 & Quetiapine initiation & YES \\
\hline 49 & $\begin{array}{l}\text { Haloperidol and } \\
\text { patient with heart } \\
\text { attack }\end{array}$ & 71 & Switching to quetiapine & YES \\
\hline $50-61$ & $\begin{array}{l}\text { Other } \\
\text { inteventions } \\
\text { which were not } \\
\text { reported } \\
\text { separately (e.g. } \\
\text { monitoring) }\end{array}$ & $\begin{array}{l}\text { Different } \\
\text { age }\end{array}$ & Different interventions & YES \\
\hline
\end{tabular}

\section{Discussion}

This study is the first in Central Europe to examine clinical pharmacist interventions in interdisciplinary ward rounding at a psychiatric hospital. The results from Slovenia are widely applicable to countries with comparable healthcare systems, such as those in Central, Southeastern, and Eastern Europe. Our main 
finding is that the clinical pharmacist recommendations had a high acceptance rate and were maintained at follow-up.

The first important result is the high acceptance rate compared to medication review services. Pharmacist participation in an interdisciplinary ward rounding was shown to be significantly associated with decreased medication errors/occupied bed/year in a study of over 1,000 US hospitals [10]. The acceptance rate in ward rounding at $93.7 \%$ in this study is notably higher than in our two previous studies on a primary setting medication review service with an acceptance rate of $48.6 \%$ and $42.8 \%$ in which suggestions were confirmed or rejected by general practitioners (GPs) [13, 14]. A higher acceptance rate of $88.0 \%$ was found in a 2014 study by Stuhec on a medication review service in a Slovenian psychiatric hospital [15]. While a medication review service alone may improve the quality of care received by psychogeriatric patients through reducing the number of medications, pDDIs, PIMs and improving treatment guideline adherence [14], the differences in acceptance rates suggest that the benefits from clinical pharmacists may be increased if they are provided with greater access to psychiatrists, who are frequently the prescribers of psychotropics. This can be achieved either through closer collaboration in a hospital (as opposed to a primary care setting) or through direct inclusion in ward rounding. Most accepted recommendations were maintained 3 months after discharge, so the recommendations were positively accepted by psychiatrists and patients, although outcomes were not measured.

Our second most important finding is that pharmacist recommendations minimize DRPs. The pharmacist's recommendations in this study addressed $56 \%$ of the expressed DRPs. The most frequent recommendations in our study were dose adjustments in $37.8 \%(N=119)$ of cases, followed by medication initiation $24.4 \%(N=77)$, medication discontinuation $24.4 \%(N=77)$ and other interventions $(13.3 \%, N=42)$. A 2019 study by Stuhec et al. had a similar distribution of intervention types and overall found that the clinical pharmacist identified several expressed DRPs, which had a positive impact on the patients' quality of life, although the acceptance rate was lower (29.2\%) than in our current study [8]. These differences may be due to how a clinical pharmacist is included in the treatment process in ward rounding as opposed to a medication review. During ward rounding, a clinical pharmacist can communicate with psychiatrists, patients, and nurses and can raise recommendations several times. Getting from recommendations to actions is lengthier in medication reviews, as the recommendations are sent out to the GP, who may discuss them with a psychiatrist.

Most interventions (40.6\%) were provided in the psychogeriatric ward, where patients were treated with excessive polypharmacy. This is similar to studies in primary care settings that show most clinical pharmacist recommendations were given for psychogeriatric patients $[8,13]$. Interestingly, interventions at the addiction department constituted $26.0 \%$ of the interventions and were mostly benzodiazepine discontinuations or related to non-psychiatric diseases (e.g., hypertension). The difference in interventions between departments shows that a clinical pharmacist in the interdisciplinary medical team can provide different specific benefits for each particular psychiatric hospital department. 
The third important finding is that the clinical pharmacist in our study provided recommendations on pharmacotherapy in general and not exclusively on mental health disorders. While such recommendations were the most frequent, recommendations on cardiovascular, pain-related, and other conditions were also provided. This shows that a clinical pharmacist can be a versatile addition to the interdisciplinary medical team. For example, all 22 antibiotic-related recommendations in our study were accepted. The clinical pharmacist recommended the discontinuation of quinolones (e.g., ciprofloxacin, levofloxacin, moxifloxacin) and cefuroxime and nitrofurantoin were added for lower urinary tract infection $\mathrm{L}(\mathrm{UTI})$. These recommendations are in line with treatment guidelines, because quinolones are discouraged as a first-line treatment, in particular for patients with mental disorders because of possible drug-drug interactions and adverse events [16, 17]. Some combinations (e.g., with duloxetine) are even contraindicated with ciprofloxacin. Our findings on antibiotics are similar to a Slovenian prospective study in a psychiatric hospital, that found the most commonly prescribed antibiotics were co-amoxiclav (36.5\% of cases) and co-trimoxazole (25.7\%), ciprofloxacin (12.2\%) and nitrofurantoin $(6.80 \%)$, and detected important DDIs in 17 out of 74 patients ( $23 \%$ or $4.48 / 100$ admissions), which were most frequently the combination of co-trimoxazole and quetiapine, and of ciprofloxacin and olanzapine [18]. The antibiotic-related pharmacist recommendations in our study were evidence-based, as the first-line treatment for psychogeriatric patients was cefuroxime (few DDIs and few adverse events) and nitrofurantoin (efficacy, few DDIs). The safest drugs for patients with mental disorders are penicillins, cephalosporins, and nitrofurantoin; macrolides and quinolones should be used with great caution $[16,18]$. The recommendations were also effective insofar as infections did not reoccur 3 months after discharge.

The fourth important finding is that the recommendations in our study were most frequently related to antipsychotics. The acceptance rate was much higher than in previous studies in a primary care setting, which may be due to a different working environment [14]. Interestingly, many interventions were connected with APP that guidelines discourage $[19,20]$. Our study found APP combinations of aripiprazole, levomepromazine and zuclopentixol, of olanzapine with aripiprazole or haloperidol, and of quetiapine with haloperidol, sulpiride, clozapine or risperidone. The clinical pharmacist recommendations were evidence-based as APP should be only considered after clozapine treatment when possible [20, 21, 22]. The results show that the clinical pharmacist reduced the use of APP and often suggested antipsychotic discontinuation in cases of excessive APP, in line with the results by Suzuki et al. that APP may be replaced with antipsychotic monotherapy in most cases [23]. A Finnish nationwide cohort study of schizophrenia patients found that the hazard ratio of psychiatric rehospitalization was $7 \%$ lower during any polypharmacy than any monotherapy period ( $\mathrm{HR}, 0.93 ; 95 \% \mathrm{Cl}, 0.91-0.95 ; p<0.001)$, but that the difference may be clinically insignificant. Aripiprazole with clozapine was associated with the lowest risk of rehospitalization, so polypharmacy may be a feasible treatment option for schizophrenia (e.g., clozapine + aripiprazole, any long-acting antipsychotic + olanzapine and clozapine + olanzapine). However, the results for clozapine monotherapy were not substantially worse than those of the best polypharmacy option [24]. Many interventions were focused on the indication for antipsychotic and insomnia treatment. These results are in line with the clinical guidelines for antipsychotic use and insomnia treatment, according to which quetiapine and olanzapine are not a first-line treatment, 
especially for insomnia, because the evidence is very weak and adverse events could be problematic [25, 26]. Many patients treated with antipsychotics experience various adverse events associated with their use [27]. Adverse events are even more important in elderly patients, since they often have multiple diseases, including cardiovascular diseases. The results of our study show that the clinical pharmacist suggested many different recommendations including olanzapine discontinuation in APP (or for cases without indication), which can reduce the risk of important cardiovascular adverse events in a long-term treatment (e.g., weigh gain, QT prolongation and diabetes). These interventions were also maintained 3 months after discharge, suggesting they were effective and well tolerated.

This study also has many important limitations which should be discussed, mostly due to the selection criteria, minimum exclusion criteria and non-randomized conditions. The study is retrospective and nonrandomized, so causal relationships cannot be established. Patients were not monitored over a longer period of time (e.g., eight months), limiting the scope of our results. Another limitation is the population heterogeneity that increases intervariability as we included patients with various mental disorders. Another source of selection bias stems from the inclusion of patients with polypharmacy and comorbidities. The sample size used in this study was small and not pre-calculated. We also did not measure clinical outcomes and other interventions (e.g., medication review). These limitations could be overcome with prospective studies in real clinical settings. Despite the limitations, our study is the first to the best of our knowledge in the EU to examine the impact of clinical pharmacists in interdisciplinary team rounding in a psychiatric hospital.

\section{Conclusions}

Clinical pharmacist participation in interdisciplinary team rounds in a psychiatric hospital led to fewer DRPs with a very high acceptance rate. Their recommendations were mostly evidence-based and maintained at a 3-month follow-up. More countries across the EU could adopt this practice to improve outcomes for patients with mental disorders in psychiatric hospitals. Additional research with larger samples or a prospective design would be needed to replicate the positive results.

\section{Declarations}

\section{Acknowledgements}

None.

\section{Author Contributions Statement}

Conceived and designed the study: MS, VT. Collected the data: VT. Analyzed the data: MS, VT. Drafted the manuscript: MS, VT. Commented the draft of the manuscript: all authors. Read and approved the final version of the manuscript: all authors.

\section{Funding}


The author MS acknowledges the financial support from the Slovenian Research Agency for manuscript writing (research core funding No. P3-0036, Biopsychosocial model of quality of life).

\section{Competing interests}

The authors declare no competing interests.

\section{References}

\section{References:}

1. WHO Global Burden of Disease. 2004 Update (World Health Organization, Geneva, 2008). [accessed Feb 5, 2021] http://www.who.int/healthinfo/global_burden_disease/GBD_report_2004update_full.pdf

2. Wittchen, H. U. et al. The size and burden of mental disorders and other disorders of the brain in Europe 2010. Eur Neuropsychopharmacol. 21, 655-657 (2010).

3. Meesters, P. D. et al. Schizophrenia spectrum disorders in later life: prevalence and distribution of age at onset sex in a dutch catchment area. Am J Geriatr Psychiatry. 20, 18-28 (2012).

4. Bole, C. B., Pišlar, M., Mrhar, A. \& Tavčar, R. Prescribing patterns for inpatients with schizophrenia spectrum disorders in a psychiatric hospital in Slovenia: Results of 16-month prospective, noninterventional clinical research. Psychiatr Danub. 29, 155-161 (2017).

5. Taipale, H. et al. 20-year follow-up study of physical morbidity and mortality in relationship to antipsychotic treatment in a nationwide cohort of 62,250 patients with schizophrenia (FIN20). World Psychiatry. 19, 61-68 (2020).

6. Adler, D. A. et al. The impact of a pharmacist intervention on 6-month outcomes in depressed primary care patients. Gen Hosp Psychiatry. 26, 199-209 (2004).

7. Finley, P. R., Bluml, B. M., Bunting, B. A. \& Kiser, S. N. Clinical and economic outcomes of a pilot project examining pharmacist-focused collaborative care treatment for depression. J Am Pharm Assoc. 51, 40-49 (2011).

8. Stuhec, M., Bratović, N. \& Mrhar, A. Impact of clinical pharmacist's interventions on pharmacotherapy management in elderly patients on polypharmacy with mental health problems including quality of life: A prospective non-randomized study. Sci Rep. 9, 16856 (2019).

9. Gunterus, A., Lopchuk, S., Dunn, C., Floyd, R. \& Normandin, B. Quantitative and economic analysis of clinical pharmacist interventions during rounds in an acute care psychiatric hospital. Ment Health Clin. 6, 242-247 (2016).

10. Bond, C. A., Raehl, C. L. \& Franke, T. Clinical pharmacy services, hospital pharmacy staffing, and medication errors in United States hospitals. Pharmacotherapy. 22, 134-147 (2002).

11. Horvat, N. \& Kos, M. Development and validation of the Slovenian drug-related problem classification system based on the PCNE classification V 6.2. Int J Clin Pharm. 38, 950-959 (2016).

12. von Elm, E. et al. STROBE Initiative. The Strengthening the Reporting of Observational Studies in Epidemiology (STROBE) statement: guidelines for reporting observational studies. J Clin Epidemiol. 
61, 344-349 (2008).

13. Stuhec, M., Gorenc, K. \& Zelko, E. Evaluation of a collaborative care approach between general practitioners and clinical pharmacists in primary care community settings in elderly patients on polypharmacy in Slovenia: a cohort retrospective study reveals positive evidence for implementation. BMC Health Serv Res. 19 (1), 118 (2019).

14. Stuhec, M. \& Gorenc, K. Positive impact of clinical pharmacist interventions on antipsychotic use in patients on excessive polypharmacy evidenced in a retrospective cohort study. Global Psychiatry. 2, 155-163 (2019).

15. Stuhec, M. Pharmacotherapy review as a safety and cost tool in patients management in Slovenian psychiatric hospital. V: abstracts of the 27th ECNP congress, Berlin, Germany, 18-21 October 2014. Eur Neuropsychopharmacol. 24, S735-6 (2014).

16. Gupta, K. et al. International clinical practice guidelines for the treatment of acute uncomplicated cystitis and pyelonephritis in women: A 2010 update by the Infectious Diseases Society of America and the European Society for Microbiology and Infectious Diseases. Clin Infect Dis. 52, e103-120 (2011).

17. Štuhec, M. et al. Potential drug interactions with antibacterials in long-term care facilities analyzed by two interaction checkers. Int J Clin Pharm. 41, 932-938 (2019).

18. Beovic, B. et al. Antibiotic Prescribing in Psychiatric Hospitals and Interactions between Antibiotics and Psychotropic Drugs: A Prospective Observational Study. Infect Control Hosp Epidemiol. 37, 233235 (2016).

19. Stahl, S. M. Emerging guidelines for the use of antipsychotic polypharmacy. Rev Psiquiatr Salud Ment. 26, 97-100 (2013).

20. Howes, O. D. et al. Adherence to treatment guidelines in clinical practice: study of antipsychotic treatment prior to clozapine initiation. Br J Psychiatry. 201, 481-485 (2012).

21. Hasan, A. et al. World Federation of Societies of biological psychiatry (WFSBP) task force on treatment guidelines for schizophrenia. Guidelines for biological treatment of schizophrenia, part 1: update 2012 on the acute treatment of schizophrenia and the management of treatment resistance. World Federation of Societies of biological psychiatry (WFSBP). World J Biol Psychiatry. 13, 318378 (2012).

22. Taylor, D. M., Young, C. \& Paton, C. Prior antipsychotic prescribing in patients currently receiving clozapine: a case note review. J Clin Psychiatry. 64, 30-34 (2003).

23. Suzuki, T., Uchida, H., Watanabe, K., Yagi, G. \& Kashima, H. A clinical case series of switching from antipsychotic polypharmacy to monotherapy with a second-generation agent on patients with chronic schizophrenia. Prog Neuropsychopharmacol Biol Psychiatry. 28, 361-369 (2004).

24. Tiihonen, J. et al. Association of Antipsychotic Polypharmacy vs Monotherapy With Psychiatric Rehospitalization Among Adults With Schizophrenia. JAMA psychiatry. 76, 499-507 (2019).

25. Wilson, S. J. British Association for Psychopharmacology consensus statement on evidence-based treatment of insomnia, parasomnias and circadian rhythm disorders. J Psychopharmacol. 24, 1577- 
1601 (2010).

26. Anderson, S. L. \& Vande Griend, J. P. Quetiapine for insomnia: a review of the literature. Am J Health Syst Pharm. 71, 394-402 (2014).

27. Krause, M. et al. Antipsychotic drugs for elderly patients with schizophrenia: A systematic review and meta-analysis. European neuropsychopharmacology: the journal of the European College of Neuropsychopharmacology. 28, 1360-1370 (2018).

\section{Figures}



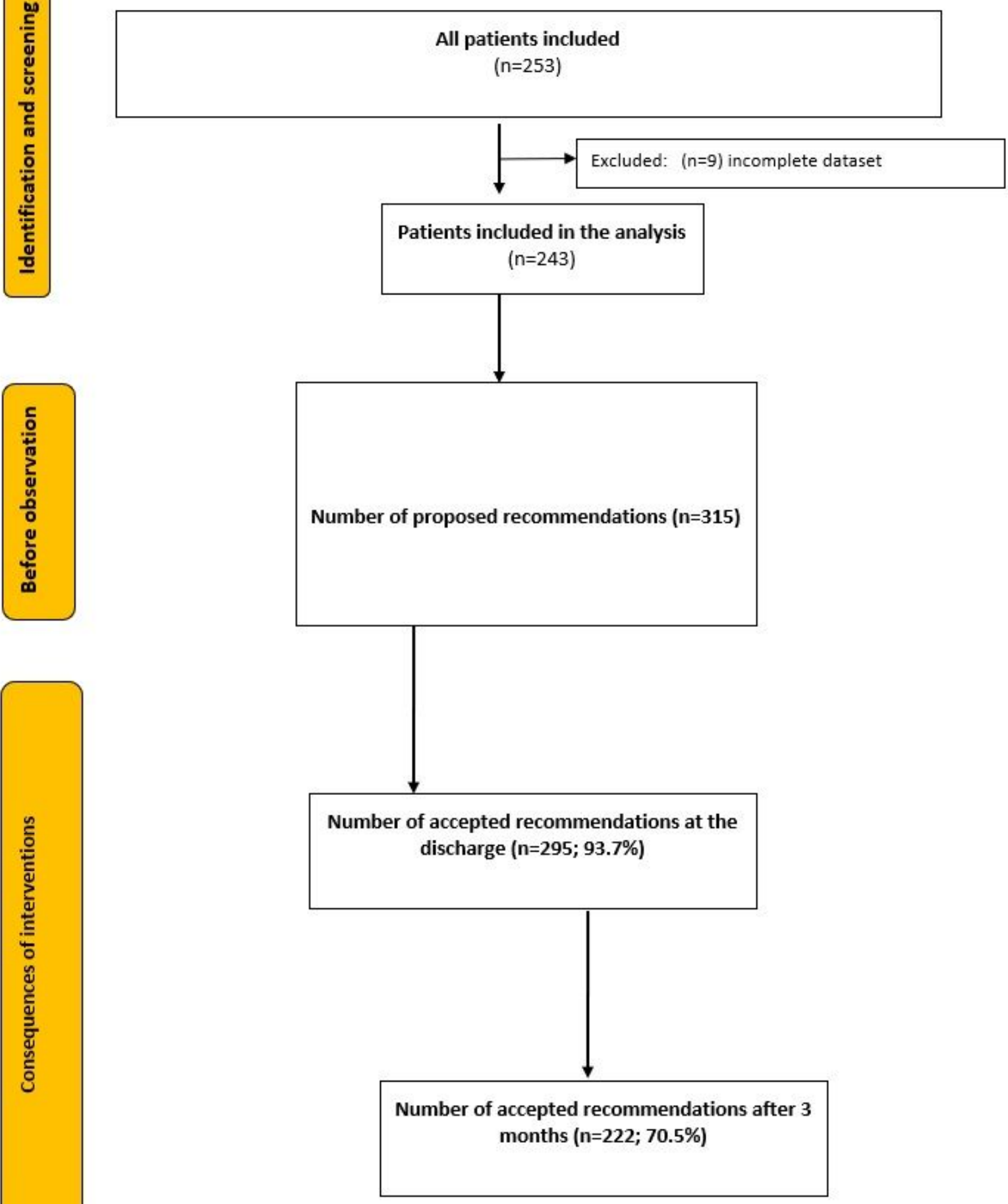

\section{Figure 1}

Flowchart. 